\title{
Intravitreal triamcinolone for intraocular inflammation and associated macular edema
}

\author{
Steven M Couch \\ Sophie J Bakri \\ Mayo Clinic Department \\ of Ophthalmology, Mayo Clinic, \\ Rochester, MN, USA
}

\begin{abstract}
Triamcinolone acetonide (TA) is a corticosteroid that has many uses in the treatment of ocular diseases because of its potent anti-inflammatory and anti-permeability actions. Intraocular inflammation broadly referred to as uveitis can result from several causes, including the immune system and after ophthalmic surgery. One of the most common reasons for vision loss with uveitis is macular edema. TA has been used for many years as an intravitreal injection for the treatment of ocular diseases. Several case control studies have been reported showing the efficacy of TA in the treatment of intraocular inflammation and associated macular edema caused by Behcet's disease, Vogt-Koyanagi-Harada syndrome, sympathetic ophthalmia and white dot syndromes. It has also been shown efficacious in cases of pars planitis and idiopathic posterior uveitis. Some authors have reported its use in postoperative cystoid macular edema. Many of the studies on the use of TA in controlling intraocular inflammation and concomitant macular edema showed its effect to be transient in many patients requiring reinjection. Complications can arise from intravitreal injection of TA including elevated intraocular pressure and cataract. Rarely, it can be associated with infectious and non-infectious endophthalmitis. TA may be useful as an adjuvant in the treatment of uveitis and its associated macular edema, especially in patients resistant or intolerant to standard treatment.
\end{abstract}

Keywords: triamcinolone acetonide, Behcet's disease, sympathetic ophthalmia, Vogt-Koyanagi-Harada syndrome, white dot syndromes, uveitis, cataract surgery, macular edema, endophthalmitis

Triamcinolone acetonide (TA) is a water-insoluble corticosteroid that is used extensively in many fields of medicine, including ophthalmology. It can be administered multiple ways for ocular disease, including injection under Tenon's capsule, into the retrobulbar space or directly into the vitreous. TA has been advocated for both medical and surgical diseases of the eye. Its use as an intravitreal injection was first made popular by Machemer in an attempt to prevent cellular proliferation after retinal detachment surgery. ${ }^{1}$ Throughout decades of use, intravitreal TA has been adopted for many indications, including uveitis, vasculitis, proliferative vitreoretinopathy, macular degeneration and a number of causes for macular edema. ${ }^{2,3,4,5,6,7}$

Corticosteroids are well known anti-inflammatory agents used in many facets of medicine. They inhibit phospholipase A2 induction through lipocortin production. ${ }^{8,9}$ Corticosteroids have also been shown to downregulate many inflammatory mediators including multiple interleukins, prostaglandins and tumor necrosis factor. ${ }^{10,11}$ In addition to dampening the inflammatory response, corticosteroids have anti-angiogenic, vasoconstrictive and anti-permeability effects. ${ }^{12,13,14}$ Within the eye, corticosteroids help maintain the blood-retinal barrier and facilitate reabsorption of exudates. ${ }^{15} \mathrm{TA}$ is a synthetic corticosteroid that is five times more potent than equivalent doses of prednisone. ${ }^{16}$ TA specifically has been shown to have profound anti-angiogenic effects. ${ }^{17}$ TA has gained favor in ophthalmology because 
its relatively small particles can be injected in or around the eye and its duration of action is several months.

TA for ophthalmic use can be prepared and administered in multiple ways. The suspension can be injected subconjunctivally, into the subtenons space or as a retrobulbar injection. However, variable intraocular concentrations of TA are obtained since the diffusion of the particles is limited by Tenon's capsule and the sclera. To obtain predictable intraocular concentrations, direct treatment of intraocular inflammation can be achieved through intravitreal injections. Several formulations are available for intraocular injection. Trisence $^{\circledR}$ (Alcon, Fort Worth, TX, USA) is a commercially available preservative-free preparation of TA that is FDA approved for intraocular use. The concentration of TA is $40 \mathrm{mg} / \mathrm{mL}$ and recommended dosing is $1-4 \mathrm{mg}(25-100 \mu \mathrm{L})$. Trivaris $^{\circledR}$ (Allergan, Irvine, CA, USA) is another commercially available preservative-free TA preparation available as a single use syringe for intravitreal injection. Instead of a suspension, Trivaris ${ }^{\circledR}$ is a gel preparation and has a concentration of $80 \mathrm{mg} / \mathrm{mL}$. Finally, Kenalog ${ }^{\circledR}$ (Bristol-Myers Squibb, Peapack, NJ, USA) is available for use off-label. It can be used in its provided form, but many retinal specialists prefer that the preservative is removed by a compounding pharmacy prior to administration.

Uveitis is a broad term used to describe intraocular inflammation specifically within the iris, ciliary body or choroid. Uveitis can be classified many different ways. Anterior uveitis implies inflammation in the iris or anterior ciliary body, intermediate uveitis describes inflammation in the posterior ciliary body and associated retina, and inflammation in the choroid is described as posterior uveitis. Causes of this complex inflammatory cascade can include infectious, traumatic, immune-mediated or surgically induced. Intraocular inflammation can lead to vision loss through many mechanisms including retinal inflammation, optic nerve inflammation and macular edema. One of the responses to inflammation within the macula is accumulation of fluid within the loosely woven fibers of Henle in the outer plexiform layer. This response, called cystoid macular edema, is the most common reason for vision loss with uveitis. Anti-inflammatories, specifically corticosteroids, are the cornerstone of treatment for uveitis and associated macular edema. Local therapy with topical drops or injections into the subconjunctival, subtenon's and retrobulbar spaces are used as treatment options; however, intraocular levels are variable. Systemic immunosuppressives, including corticosteroids, are important in the treatment of severe uveitis. For inflammation involving the posterior segment, direct treatment via intravitreal injections of corticosteroids can be used in an attempt to achieve desired predictable intraocular concentrations.

\section{Autoimmune uveitis}

Autoimmune uveitis, like other forms of autoimmune disease, is thought to occur through a breakdown in immunologic self-regulation. Complex immunologic events are involved in the development and progression of autoimmune uveitis. The location and pattern of inflammation may lead to a diagnosis; however, often the cause of autoimmune uveitis cannot be discovered. The causes of this inflammation can be isolated to the eye or may be part of a larger systemic disease. Isolated causes of uveitis include pars planitis, white dot syndromes, sympathetic ophthalmia and acute retinal necrosis. Often uveitis is a manifestation of systemic diseases including sarcoidosis, juvenile rheumatoid arthritis, inflammatory bowel disease, systemic lupus erythematosus, Behcet's disease (BD), Vogt-Koyanagi-Harada syndrome (VKH) and multiple sclerosis. The preferred treatment of uveitis depends on the location and severity of inflammation and presence of vision loss. As described previously, the most common cause of vision loss with uveitis is cystoid macular edema.

BD describes an idiopathic systemic inflammatory condition with a classic triad of uveitis, aphthous stomatitis and genital ulcers. Severe relapsing panuveitis and profound vision loss are common ocular manifestations. Systemic immunosuppressives are critical in the treatment of BD. Patients who are intolerant of systemic therapy or those whose intraocular inflammation is refractory to treatment may require eye targeted therapy. Several studies have advocated the use of intravitreal TA in the treatment of patients with BD who have refractory panuveitis with vision loss. ${ }^{18,19,20,21,22}$ In the study by Tuncer et al all of the patients given intravitreal TA had resolution of intraocular inflammation and improvement of visual acuity. ${ }^{19}$ Only one fourth of the patients had relapsing inflammation within 2 years of injection. Associated macular edema was shown to decrease in over $80 \%$ of patients described in several studies. ${ }^{20,21}$ Oghuro et al suggests that repeat intraocular TA injections may prevent recurrent attacks of uveitis with BD. ${ }^{22}$ These studies have illustrated intravitreal TA's use in refractory panuveitis associated with BD.

Sympathetic ophthalmia (SO) describes a potentially severe, vision-threatening immune-mediated panuveitis following penetrating trauma to the fellow eye. This is a potentially severe consequence of a penetrating ocular 
injury and requires lifelong treatment. Vision loss is commonly secondary to serous retinal detachments and macular swelling. Prior to the advent of corticosteroids, this disease commonly led to blindness. Traditionally, systemic immunosuppressives, including corticosteroids, are the mainstay of treatment for SO. Multiple routes of administration for corticosteroids coupled with early recognition and treatment have improved the prognosis for this disease. Several case reports illustrate favorable results with the use of intravitreal TA as treatment for both acute and chronic SO. ${ }^{23,24,25,26}$ Two cases reported of acute SO with associated serous retinal detachments, retinal edema and vision loss were treated with intravitreal TA. The vision dramatically improved and the retinal swelling significantly improved within two weeks of treatment. The patients were clinically in remission within 3 months of treatment. ${ }^{23,25}$ Jonas and Spandau describe a case of SO treated with intravitreal TA who also acutely improved both objectively and subjectively. ${ }^{24}$ After over 2 years of repeated injections, the described patient's vision has remained stable and her systemic immunosupressives have been decreased significantly. ${ }^{26}$ Because of the remote incidence of SO, randomized trials cannot be conducted; however, these cases have shown a benefit for early and continued treatment with intravitreal TA.

VKH describes a rare idiopathic systemic disease of melanocyte-containing tissues. The cutaneous manifestations of this disease include poliosis, vitiligo and alopecia. Neurologic consequences include encephalitis, tinnitus and dysacusis. The ocular complications resemble those seen with SO and include granulomatous panuveitis with severe vision loss. Like SO, systemic immunosuppressives are the cornerstone of treatment. However, like other diseases requiring systemic immunosuppressives, adverse effects of treatment are common, necessitating the use of local therapy. Several cases of VKH treated with intravitreal TA have been reported with favorable results. All of the cases reported showed a rapid improvement in vision and clinical appearance with up to 14 months of stability. ${ }^{27,28,29}$ No data on the long-term use of intravitreal TA for VKH have been reported.

Immune recovery uveitis (IRU) describes rebound ocular inflammation following an acute ocular inflammatory syndrome in a reversibly immunocompromised patient. This condition became widely recognized with the beginning of highly active antiretroviral therapy (HAART) for acquired immunodeficiency syndrome (AIDS). These patients would develop infectious retinitis and have a severe vision-threatening uveitis following treatment of the retinitis and initiation of HAART. It was found in one study to occur in up to $15 \%$ of AIDS patients following cytomegalovirus (CMV) uveitis. ${ }^{30}$ In addition to AIDS-associated IRU, other reversible causes of immune compromise including systemic chemotherapy and solid organ transplantation have been associated with IRU. Sirimaharaj et al described the use of intravitreal TA in two patients with HIV associated IRU. Both patients improved clinically and subjectively. ${ }^{31}$ One interventional case series of cystoid macular edema (CME) with IRU showed an average three-line improvement in visual acuity and improvement in macular edema 3 months following a single intravitreal TA injection. ${ }^{32}$ Because systemic immunosuppression allowed for the infectious retinitis care must be taken in treating IRU with medications that have systemic consequences, which would suggest the use of highly directed local therapy like intravitreal TA.

Multifocal areas of inflammation within the retina and choroid characterized by white dots are generally classified as white dot syndromes. The white dot syndromes then can be organized into separate categories depending on pattern and location of inflammatory lesions. These categories include acute posterior multifocal placoid pigment epitheliopathy (AMPPE), multiple evanescent white dot syndrome (MEWDS), birdshot chorioretinopathy, punctate inner choroidopathy (PIC), serpiginous choroiditis and multifocal choroiditis and panuveitis (MCP). The syndromes that more commonly manifest with severe visual loss and macular edema include birdshot chorioretinopathy and serpiginous choroiditis. They are characterized by ocular inflammation that is recalcitrant and reoccurring. Most commonly these syndromes are treated with systemic immunosuppression; however additional or alternative treatment may be required. Serpiginous choroiditis is characterized by bilateral inflammation with yellow subretinal infiltrates extending from the optic disc in a geographic pattern. ${ }^{33}$ Several cases have been reported of rapid remission of inflammation after intravitreal TA injection. ${ }^{34,35,36}$ The inflammation has been reported to be decreased for up to 10 months. ${ }^{35}$ In addition, cases of associated macular edema rapidly resolved after TA. ${ }^{34,36}$ Birdshot retinochoroidopathy, also called vitiliginous, is characterized by bilateral cream-colored lesions in the posterior pole. It is has a presumed autoimmune etiology as it is highly associated with HLA-A29. Shah and Brandley describe a case of birdshot retinochoroidopathy that was managed over a 3-year period with repeated intravitreal TA injections given every 10 months. This was done because the patient refused systemic therapy and the patient's vision and clinical exam remained under control with this treatment. ${ }^{37}$ 
Martidis et al described two cases of CME due to birdshot chorioretinopathy successfully treated with intravitreal TA. ${ }^{38}$ While it is an uncommon manifestation of AMPPE, Yenerel et al describe a case of late onset AMPPE presenting with CME that was successfully treated with intravitreal TA. ${ }^{39}$ White dot syndromes are uncommon but the vision loss associated with them can be profound. Intravitreal TA can be considered in cases when inflammation is recurrent despite systemic immunosuppression or the treatment is not tolerated.

\section{Idiopathic uveitis}

While it is important to rule out autoimmune and infectious causes of uveitis, often intraocular inflammation can occur without an identifiable reason. This can be especially true for patients with intermediate uveitis but can also occur with posterior uveitides. Pars planitis refers to idiopathic intermediate uveitis. Like the other uveitides, the main cause of vision loss is cystoid macular edema. Despite effective treatment of inflammation with systemic immunosuppressives the macular edema may persist. Treatment of CME with idiopathic uveitis classically is with posterior sub-tenons (PST) deposits of steroids, but a recent study by Choudhry showed no difference in outcomes including recovery of visual acuity and angiographic resolution of macular edema between PST-TA and intravitreal TA. ${ }^{40}$ One case report of pars planitis by Degenring and Jonas illustrates effective resolution of CME with the use of intravitreal TA in a patient who was intolerant to systemic immunosuppression. ${ }^{41}$ While not evaluated separately, idiopathic uveitis is commonly evaluated in combination with other etiologies of uveitis and uveitic CME. A prospective case series by Ozkiris showed no significant difference in visual outcomes and resolution of vitreous inflammation between intravitreal injection of $8 \mathrm{mg}$ TA and oral corticosteroids. ${ }^{42}$ Several studies have been performed looking at the efficacy of intravitreal TA in the treatment of uveitic CME. ${ }^{41,43,44,45,46,47,48,49}$ The dose of the TA used ranged from $2 \mathrm{mg}$ to $4 \mathrm{mg}$ injected intravitreally. Regardless of the dose many studies showed that intravitreal TA rapidly helped macular edema and consequently visual acuity; however, in some cases this effect appeared to be transient. Das-Bhaumik and Jones showed the efficacy of $2 \mathrm{mg}$ dosing of TA in causing the resolution of CME in $80 \%$ of patients and resolution of intraocular inflammation in only half. ${ }^{47}$ Kok et al showed a statistically significant improvement in visual acuity in patients under 60 years old treated with $4 \mathrm{mg}$ of intravitreal TA. The greatest improvement in their patients was within the first 4 weeks of treatment. ${ }^{46}$
Sorensen et al describe a relationship between efficacy of intravitreal TA and etiology of uveitis. After intravitreal TA injection they showed resolution of CME secondary to uveitis and diabetic macular edema but not chronic pseudophakic CME. ${ }^{50}$ These studies suggest a possible role for intravitreal TA in helping control refractory uveitis and CME.

\section{Postsurgical inflammation and macular edema}

Intraocular surgery can have many complications but one of the more common causes of unfavorable visual outcomes is postoperative CME. The precise pathogenesis of postoperative CME is likely multifactorial and presumably includes inflammation. ${ }^{51,52,53,54}$ Cataract surgery is a common culprit and when postoperative pseudophakic CME occurs it is referred to as Irvine-Gass syndrome. ${ }^{51}$ Through evolution of cataract surgery from extracapsular extraction to phacoemulsification the incidence of CME has decreased. ${ }^{55,56}$ Commonly pseudophakic CME resolves spontaneously or with topical treatment. Many treatments have been attempted for chronic nonresponsive postoperative CME including topical steroids, periocular deposits of steroids, topical nonsteroidal anti-inflammatories, Nd:YAG vitreolysis, and vitrectomy. ${ }^{57,58,59,60,61}$ Several reports have been published showing favorable anatomic and functional outcomes after intravitreal TA for recalcitrant pseudophakic CME. ${ }^{62,63,64,65,66,67}$ Koutsandrea et al showed an increase in vision and multifocal electroretinography with significant improvement in optical coherence tomography retinal thickness after intravitreal TA. ${ }^{64}$ Several studies showed a temporary decrease in retinal thickness corresponding to better visual acuity but it recurred within several months. ${ }^{65,63}$ Sorensen et al showed no improvement in visual acuity and foveal thickness in four patients after TA for pseudophakic CME. They therefore hypothesized a difference in the efficacy of TA for CME depending on the etiology. ${ }^{50}$ Drs Jonas and Kamppeter published a case of persistent CME following penetrating keratoplasty effectively treated with intravitreal TA. ${ }^{68}$ While rare, recurrent postoperative $\mathrm{CME}$ resistant to conventional therapy can occur and intravitreal injections of TA may be helpful.

\section{Complications of TA}

Corticosteroids are notorious for many different adverse effects. The type and frequency of these effects is dependent mostly upon the route of administration. Ophthalmic consequences of local application of steroids include cataract progression and elevated intraocular pressure. 
When steroids are injected into the eye, many studies have shown a low risk of retinal detachment, vitreous hemorrhage and endophthalmitis, both infectious and noninfectious. Cataract development and progression are well known complications of steroids, especially when injected intravitreally. Newly developed cataracts from intravitreal TA generally are posterior subcapsular in location. It is important to note that uveitis itself is a risk factor for the development of cataracts. Several studies have been published showing the incidence of this to be anywhere from $29 \%$ to over $50 \%$ within 1 year of followup. ${ }^{69,70,71}$ One hypothesis is that elevated intraocular pressure (IOP) plays a role in the development of cataracts as cataract progression was seen much higher in patients whose IOP was steroid responsive. ${ }^{72}$ Multiple studies have shown the increased incidence of elevated IOP following intravitreal TA administration. ${ }^{46,47,70,73,74,75}$ One study comparing patients with and without uveitis treated with intravitreal TA showed the strongest risk factor for elevated IOP was the presence of uveitis. ${ }^{75}$ One study showed that eyes with an IOP above $15 \mathrm{~mm} \mathrm{Hg}$ were more likely to developed steroid responsive elevated pressure. ${ }^{70}$ The elevated IOP generally is controlled with temporary topical anti-glaucoma agents; however, surgical treatment to lower the IOP has been indicated in several studies. ${ }^{70,71,76,77,78}$ Endophthalmitis following injection of TA can have an infectious or non-infectious etiology. Several studies have shown the incidence of infectious endophthalmitis to be around $0.5 \%$ and all types of endophthalmitis to be around $1.1 \% .^{79,80,81}$ The term non-infectious endophthalmitis is reserved for true inflammation that is thought to represent a immunologic response to TA or its preservative, benzyl alcohol. ${ }^{82,83,84,85,86}$ Another entity referred to as pseudoendophthalmitis describes TA crystals masquerading as inflammatory cells. ${ }^{80,87}$ While there are several distinctive differences between these entities clinically, many times the clinical presentation overlaps. Non-infectious endophthalmitis generally manifests within a few days of treatment as a painless red eye with very prominent anterior chamber and vitreous reaction. Bacterial endophthalmitis generally presents up to 10 to 15 days after injection with severe pain, vision loss and prominent inflammation both externally and internally. In addition to these risks of injection several other very rare complications have been reported including retinal detachment, vitreous hemorrhage, and conjunctival necrosis. ${ }^{70,88,89}$ Complications of intravitreal TA are rare but can be serious if they occur.

TA has been used for many decades in the treatment of ocular disease and its indications continue to expand. Direct treatment of ocular inflammation with intravitreal injection limits systemic adverse effects. Because of its potent antiinflammatory effects it can be used as an adjuvant in the treatment of recalcitrant uveitis and associated CME. It also shows promise as a treatment of uveitis in patients intolerant of other treatments. With a relatively low risk of adverse effects, it is regarded as safe in the treatment of uveitis and its associated macular edema.

\section{Disclosures}

The authors have no conflicts of interest to disclose.

\section{References}

1. Machemer R, Sugita G, Tano Y. Treatment of intraocular proliferations with intravitreal steroids. Trans Am Ophthalmol Soc. 1979;7:171-8.

2. Jonas JB, Hayler JK, Panda-Jones S. Intravitreal injection of crystaline cortisone as adjunctive treatment of proliferative vitreoretinopathy. Br J Ophthalmol. 2000;85:1064-7.

3. Munir WM, Pulido JS, Sharma MC, Buerk BM. Intravitreal triamcinolone for treatment of complicated proliferative diabetic retinopathy and proliferative vitreoretinopathy. Can J Ophthalmol. 2005;40:598-604.

4. Jonas JB, Kressig I, Kamppeter B, Degenrin RF. Intravitreal triamcinolone acetonide for the treatment of intraocular oedematous and neovascular diseases. Ophthalmology. 2004;101:113-20.

5. Gillies MC, Larsson J. The effect of intravitreal triamcinolone on foveal edema in exudative macular degeneration. Am J Ophthalmol. 2007; 144:134-5.

6. Jonas JB, Kreissig I, Soefker A, Degenring RF. Intravitreal injection of triamcinolone for diffuse diabetic macular edema. Arch Ophthalmol. 2003;121:57-61.

7. Martidis A, Duker DJ, Greenberg PB, et al. Intravitreal triamcinolone for refractory diabetic macular edema. Ophthalmology. 2002;109:920-7.

8. Argenti D, Jensen BK, Hensel R, et al. A balance study to evaluate the biotransformation and excretion of [14C] triamcinolone acetonide following oral administration. J Clin Pharmacol. 2000;40:770-80.

9. Duguid IG, Boyd AW, Mandel TE. Adhesion molecules are expressed in the human retina and choroid. Curr Eye Res. 2000;11(Suppl):153-9.

10. Floman N, Zor U. Mechanism of steroid action in ocular inflammation: inhibition of prostaglandin production. Invest Ophthalmol. 1977;16:69-73.

11. Lewis GD, Campbell WB, Johnson AR. Inhibition of prostaglandin synthesis by glucocorticoids in human endothelial cell. Endocrinology. 1986;199:62-9.

12. Fischer S, Renz D, Schaper W, Karliczek GF. In vitro effects of dexamethasone on hypoxia-induced hyperpermeability and expression of vascular endothelial growth factor. Eur J Pharmacol. 2001;411(3):231-43.

13. Sommer A, Veraart J, Neumann M, et al. Evaluation of vasoconstrictive effects of topical steroids by lasesr-Doppler-perfusion-imaging. Acta Derm Venereol. 1998;78:15-8.

14. Bandi N, Kompella UB. Budesonide reduces vascular endothelial growth factor secretion and expression in airway (Calu-1) and alveolar (A549) epithelial cells. Eur J Pharmacol. 2001;425:109-16.

15. Wilson CA, Berkowitz BA, Sato Y, et al. Treatment with intravitreal steroid reduces blood-retinal barrier breakdown due to retinal photocoagulation. Arch Ophthalmol. 1992;110:1155-9.

16. Jermak CM, Dellacroce JT, Heffez J, Peyman G. Triamcinolone acetonide in ocular therapeutics. Surv Ophthalmol. 2007;52(5):503-22.

17. Wang YS, Friedrichs U, Eichler W, Hoffmann S, Wiedemann P. Inhibitory effects of triamcinolone acetonide on bFGF-induced migration and tube formation in choroidal microvascular endothelial cells. Graefes Arch Clin Exp Ophthalmol. 2002;240(1):42-8. 
18. Kramer M, Ehrlich R, Snir M, et al. Intravitreal injections of triamcinolone acetonide for severe vitritis in patients with incomplete Behcet's disease. Am J Ophthalmol. 2004;138(4):666-7.

19. Tuncer S, Yilmaz S, Urgancioglu M, Tugal-Tutkun I. Results of intravitreal triamcinolone acetonide (IVTA) injection for the treatment of panuveitis attacks in patients with Behcet disease. J Ocul Pharmacol Ther. 2007;23(4):395-401.

20. Atmaca LS, Yalcindag FN, Ozdemir O. Intravitreal triamcinolone acetonide in the management of cystoid macular edema in Behcet's disease. Graefes Arch Clin Exp Ophthalmol. 2007;245(3):451-6.

21. Karacorlu M, Mudun B, Ozdemir H, Karacorlu SA, Burumcek E. Intravitreal triamcinolone acetonide for the treatment of cystoid macular edema secondary to Behcet disease. Am J Ophthalmol. 2004;138(2):289-91.

22. Ohguro N, Yamanaka E, Otori Y, Saishin Y, Tano Y. Repeated intravitreal triamcinolone injections in Behcet disease that is resistant to conventional therapy: one-year results. Am J Ophthalmol. 2006;141(1):218-20.

23. Ozdemir H, Karacorlu M, Karacorlu S. Intravitreal triamcinolone acetonide in sympathetic ophthalmia. Graefes Arch Clin Exp Ophthalmol. 2005;243(7):734-6.

24. Jonas JB, Spandau UH. Repeated intravitreal triamcinolone acetonide for chronic sympathetic ophthalmia. Acta Ophthalmolo Scand. 2006;84(3):436.

25. Chan RV, Seiff BD, Lincoff HA, Coleman DJ. Rapid recovery of sympathetic ophthalmia with treatment augmented by intravitreal steroids. Retina. 2006;26(2):243-24.

26. Jonas JB. Intravitreal triamcinolone acetonide for treatment of sympathetic ophthalmia. Am J Ophthalmol. 2004;137(2):367-8.

27. Karacorlu M, Arf Karacorlu S, Ozdemir H. Intravitreal triamcinolone acetonide in Vogt-Koyanagi-Harada sydrome. Eur J Ophthalmol. 2006;16(3):481-3.

28. Andrade RE, Muccioli C, Farah ME, Nussenblatt RB, Belfort R $\mathrm{Jr}$. Intravitreal triamcinolone in the treatment of serous retinal detachment in Vogt-Koyanagi-Harada syndrome. Am J Ophthalmol. 2004;137(3):572-4.

29. Moreker MR, Lodhi SA, Pathengay A. Role of intravitreal triamcinolone as an adjuvant in the management of Vogt-Koyanagi-Harada disease. Indian J Ophthalmol. 2007;55(6):479-80.

30. Jabs DA, Van Natta ML, Kempen JH. Characteristics of patients with cytomegalovirus retinitis in the era of highly active antiretroviral therapy. Am J Ophthalmol. 2002;133:48-61.

31. Sirimaharaj M, Robinson MR, Zhu M, et al. Intravitreal injection of triamcinolone acetonide for immune recovery uveitis. Retina. 2006;26(5):578-80.

32. Morrison VL, Kozak I, LaBree LD, et al. Intravitreal triamcinolone acetonide for the treatment of immune recovery uveitis macular edema. Ophthalmology. 2007;114(2):334-9.

33. Weiss H, Anlessly WJ, Shield JA. The clinical course of serpiginous retinochoroidopathy. Am J Ophthalmol. 1979;87:133-42.

34. Adiguzel U, Sari A, Ozmen C, Oz O. Intravitreal triamcinolone acetonide treatment for serpiginous choroiditis. Ocul Immunol Inflamm. 2006;14(6):375-8.

35. Pathengay A. Intravitreal triamcinolone acetonide in serpiginous choroidopathy. Indian J Ophthalmol. 2005;53(1):77-9.

36. Karacorlu S, Ozdemir H, Karacorlu M. Intravitreal triamcinolone acetonide in serpiginous choroiditis. Jpn J Ophthalmol. 2006;50:284-98.

37. Shah A, Branley M. Use of intravitreal triamcinolone in the management of birdshot retinochoroidopathy associated with cystoid macular oedema: a case study over a three-year period. Clin Exp Ophthalmol. 2005;33(4):442-4.

38. Martidis A, Duker JS, Puliafito CA. Intravitreal triamcinolone for refractory cystoid macular edema with birdshot retinochoroidopathy. Arch Ophthalmol. 2001;119:1380-3.

39. Yenerl NM, Gorgun E, Dinc UA, Oncel M. Treatment of cystoid macular edema due to acute posterior multifocal placoid pigment epitheliopathy. Ocul Immunol Inflamm. 2008;16:67-71.
40. Choudhry S, Ghosh S. Intravitreal and posterior subtenon triamcinolone acetonide in idiopathic bilateral uveitic macular oedema. Clin Exp Ophthalmol. 2007;35(8):713-8.

41. Degenring RF, Jonas JB. Intravitreal injection of triamcinolone acetonide as treatment for chronic uveitis. Br J Ophthalmol. 2003;87(3):361.

42. Ozkiris A. Intravitreal triamcinolone acetonide injection for the treatment of posterior uveitis. Ocul Immunol Inflamm. 2006;14(4):233-8.

43. Okhravi N, Morris A, Kok HS, et al. Intraoperative use of intravitreal triamcinolone in uveitic eyes having cataract surgery: pilot study. J Cataract Refract Surg. 2007;33(7):1278-83.

44. Angunawela RI, Heatley CJ, Williamson TH, et al. Intravitreal triamcinalone acetonide for refractory uveitic cystoid macular oedema: longterm management and outcome. Acta Ophthalmol Scand. 2005;83(5):595-9.

45. Andrews RM, Kok H, Lau C, Maycock N, McCluskey P, Lightman S. Effectiveness of intravitreal triamcinolone acetate in refractory uveitic cystoid macular oedema. Investig Ophthalmol Vis Sci. 2005;46.

46. Kok H, Lau C, Maycock N, McCluskey P, Lightman S. Outcome of intravitreal triamcinolone in uveitis. Ophthalmology. 2005;112(11):1916.e1-7.

47. Das-Bhaumik RG, Jones NP. Low-dose intraocular triamcinolone injection for intractable macular oedema and inflammation in patients with uveitis. Eye. 2006;20(8):934-7.

48. Tay-Kearney ML. Intravitreal triamcinolone acetonide injection for the treatment of posterior uveitis. Ocul Immunol Inflamm. 2006;14:201-2.

49. Kooij BV, Rothova A, de Vries P. The pros and cons of intravitreal triamcinolone injections for uveitis and inflammatory cystoid macular edema. Ocul Immunol Inflamm. 2006;14:73-85.

50. Sorensen TL, Haamann P, Villumsen J, Larsen M. Intravitreal triamcinolone for macular oedema: efficacy in relation to aetiology. Acta Ophthalmol Scand. 2005;83(1):67-70.

51. Irvine SR. A newly defined vitreous syndrome following cataract surgery. Am J Ophthal. 1953;36:599-619.

52. Irvine SR. Cystoid Maculopathy. Surv Ophthalmol. 1976;21:1-17.

53. Kraff MC, Sanders DR, Jampol LM, Lieberman HL. Factors affecting pseudophakic cystoid macular edema: five randomized trials. Am Intra-ocular Implant Soc J. 1985;11:380-5.

54. Guex-Crosier Y. The pathogenesis and clinical presentation of macular edema in inflammatory disease. Doc Ophthalmol. 1999;97:297-309.

55. Kraff MC, Sanders DR, Jampol LM, Lieberman HL. Effect of primary capsulotomy with extracapsular surgery on the incidence of pseudophakic cystoid macular oedema. Am J Ophthalmol. 1984;98:166-70.

56. Wright PL, Wilkinson CP, Balyeat HD, et al. Angiographic cystoid macular oedema after posterior chamber lens implantation. Arch Ophthalmol. 106:740-4.

57. Yannuzzi LA. A perspective on the treatment of aphakic cystoid macular oedema. Surv Ophthalmol. 1984;28:540-53.

58. Jampol LM. Pharmacologic therapy of aphakic and pseudophakic cystoid macular oedema: 1985 update. Ophthalmology. 1985;92:807-10.

59. Levy JH, Pisacona AM. Clinical experience with Nd:YAG laser vitreolysis in the anterior segment. J Cataract Refract Surg. 1987;13:548-50.

60. Suckling RD, Maslin KF. Pseudophakic cystoid macular oedema and its treatment with local corticosteroids. Aust N Z J Ophthalmol. 1988;16:353-9.

61. Pendergast SD, Magherio RR, Williams GA, Cos MS. Vitrectomy for chronic pseudophakic cystoid macular edema. Am J Ophthalmol. 1999;128:317-23.

62. Jonas JB, Kreissig I, Degenring RF. Intravitreal triamcinolone acetonide for pseudophakic cystoid macular edema. Am J Ophthalmol. 2003;136(2):384-6.

63. Boscia F, Furino C, Dammacco R, Ferreri P, Sborgia L, Sborgia C. Intravitreal triamcinolone acetonide in refractory pseudophakic cystoid macular edema: Functional and anatomic results. Eur J Ophthalmol. 2005;15(1):89-95.

64. Koutsandrea C, Moschos MM, Brouza D, Loukianou E, Apostolopoulos M, Moschos M. Intraocular triamcinolone for pseudophakic cystoid macular edema: Optical coherence tomography and multifocal electroretinography study. Retina. 2007;27(2):159-64. 
65. Benhamou N, Massin P, Haouchine B, Audren F, Tadayoni R, Gaudric A. Intravitreal triamcinolone for refractory pseudophakic macular edema. Am J Ophthal. 2003;135(2):246-9.

66. Conway MD, Canakis C, Livir-Rallatos C, Peyman GA. Intravitreal triamcinolone acetonide for refractory chronic pseudophakic cystoid macular edema. J Cataract Refract Surg. 2003;29:27-33.

67. Karacorlu M, Ozdemir H, Karacorlu S. Intravitreal triamcinolone actetonide for the treatment of chronic pseudophakic cystoid macular oedema. Acta Ophthal Scand. 2003;81:648-52.

68. Jonas JB, Kamppeter B. Intravitreal triamcinolone acetonide for persisting cystoid macular edema after penetrating keratoplasty. Cornea. 2006;25:240-1.

69. Thompson JT. Cataract formation and other complications of intravitreal triamcinolone for macular edema. Am J Ophthalmol. 2006;141(4):629-37.

70. Van Kooij B, Rothova A, de Vries P. The pros and cons of intravitrea triamcinolone injections for uveitis and inflammatory cystoid macular edema. Ocul Immunol Inflamm. 2006;14:73-85.

71. Gillies MC, Simpson JM, Billson FA, et al. Safety of an intravitreal injection of triamcinolone: results from a randomized clinical trial. Arch Ophthalmol. 2004;122:336-40.

72. Gilles MC, Kuzniarz M, Craig J, et al. Intravitreal triamcinoloneinduced elevated intraocular pressure is associated with the development of posterior subcapsular cataract. Ophthalmology. 2005;112:139-43.

73. Wingate RJ, Beaumont PE. Intravitreal triamcinolone and elevated intraocular pressure. Aust NZ J Ophthalmol. 1999;27:431-2.

74. Smithen LM, Ober MD, Maranan L, Spaide RF. Intravitreal triamcinolone acetonide and intraocular pressure. Am J Ophthalmol. 2004;138:740-3.

75. Galor A, Margolis R, Brasil OMF, et al. Adverse events after intravitreal triamcinolone in patients with and without uveitis. Ophthalmololgy. 2007;114:1912-8.

76. Detry-Morel M, Escarmelle A, Hermans I. Refractory ocular hypertension secondary to intravitreal injection of triamcinolone acetonide. Bull Soc Belge Ophthalmol. 2004;292:45-51.

77. Jonas JB, Degenring RF, Kreissig I, et al. Intraocular pressure elevated after intravitreal triamcinolone acetonide injection. Ophthalmology. 2005; 112:593-8.
78. Agrawal S, Agrawal J, Agrawal TP. Vitrectomy as a treatment for elevated intraocular pressure following intravitreal injection of triamcinolone acetonide. Am J Ophthalmol. 2004;138:679-80.

79. Moshfeghi DM, Kaiser PK, Scott IU, et al. Acute endophthalmitis following intravitreal triamcinolone acetonide injection. Am JOphthalmol. 2003;136(5):791-6.

80. Jager RD, Aiello LP, Patel SC, Cunningham ET Jr. Risks of intravitreous injection: a comprehensive review. Retina. 2004;24:676-98.

81. Bhavsar AR, Ip MS, Glassman AR. The risk of endophthalmitis following intravitreal triamcinolone injection in the DRCRnet and SCORE clinical trials. Am J Ophthalmol. 2007;144(3):454-6.

82. Bakri SJ, Shah A, Falk NS, Beer PM. Intravitreal preservative-free triamcinolone acetonide for the treatment of macular oedema. Eye. 2005;19(6):686-8.

83. Moshfeghi DM, Kaiser PK, Bakri SJ, et al. Presumed sterile endophthalmitis following intravitreal triamcinolone acetonide injection. Ophthalmic Surg Lasers Imaging. 2005;36(1):24-9.

84. Maia M, Farah ME, Belfort RN, et al. Effects of intravitreal triamcinolone acetonide injection with and without preservative. Br JOphthalmol. 2007;91(9):1122-4.

85. Nelson ML, Tennant MT, Sivalingam A, Regillo CD, Belmont JB, Martidis A. Infectious and presumed noninfectious endophthalmitis after intravitreal triamcinolone acetonide injection. Retina. 2003;23(5):686-91.

86. Jonas JB, Kreissig I, Spandau UH, Harder B. Infectious and noninfectious endophthalmitis after intravitreal high-dosage triamcinolone acetonide. Am J Ophthalmol. 2006;141(3):579-80.

87. Moshfeghi AA, Scott IU, Flynn HW, Puliafito CA. Pseudohypopyon after intravitreal triamcinolone acetonide injection for cystoid macular edema. Am J Ophthalmol. 2004;138(3):489-92.

88. Androudi S, Letko E, Meniconi M, et al. Safety and efficacy of intravitreal triamcinolone acetonide for uveitic macular edema. Ocular Immunol Inflamm. 2005;13:205-12.

89. Srinivasan S, Prasad S. Conjunctival necrosis following intravitreal injection of triamcinolone acetonide. Cornea. 2005;24(8):1027-8. 
